\title{
Rotavirus Group A Surveillance and Genotype Distribution in Russian Federation in Seasons 2012-2013
}

\author{
Olga A. Veselova, Alexandr T. Podkolzin, Dmitriy N. Petukhov, Konstantin V. Kuleshov, \\ German A. Shipulin \\ Enteric Pathogens Monitoring Group, Central Research Institute for Epidemiology, Moscow, Russia \\ Email: konstantinkul@gmail.com
}

Received 13 January 2014; revised 10 February 2014; accepted 7 March 2014

Copyright (C) 2014 by authors and Scientific Research Publishing Inc.

This work is licensed under the Creative Commons Attribution International License (CC BY). http://creativecommons.org/licenses/by/4.0/

(c) (i) Open Access

\begin{abstract}
Rotavirus infection is one of the primary causes of acute gastroenteritis in industrialized countries and may be a cause of severe disease in children. Here we present the results of analysis of specific indicators which characterize the burden of rotavirus infection in Russia such as passive surveillance data for rotavirus gastroenteritis cases (RG), the proportion of outbreaks of rotavirus per calendar month and laboratory-based data of rotavirus infection occurrence in lethal cases involving children. Specific features of rotavirus $[\mathrm{P}] \mathrm{G}$ genotypes distribution in different geographic regions of Russia from 2012 through 2013 are also provided.
\end{abstract}

\section{Keywords}

Rotavirus Infection, Surveillance, Diarrhea, Genotype Distribution

\section{Introduction}

Rotavirus infection is the leading known cause of severe gastroenteritis in infants and young children worldwide [1]-[3]. It is highly prevalent among infants, with a high percentage of rotavirus-related hospitalizations resulting in high levels of economic burden. Primary infection of infants with rotavirus infection is often accompanied by vomiting and fever which can lead to severe dehydration, in rare cases to lethal outcome. Risk group of complicated course of rotavirus gastroenteritis is immunocompromised children as well as children with concomitant pathology. Predominant fecal-oral route of transmission and low infective dose of rotavirus increases the risks of spreading of this infection in child care centers and children's hospitals. This has given rise to interest in preventive measures like vaccination [4]-[6]. It has been shown rotavirus vaccines are the only effective measure to 
decrease manifestations of rotavirus infection [7] [8]. The conclusion to include the rotavirus vaccine in national or regional vaccination schedule is based on results of economic effectiveness vaccine and the burden of rotavirus infection [9] [10].

The prevalent rotavirus vaccine RotaTeq ${ }^{\circledR}$ (Merck Sharp \& Dohme, MSD, USA) has been registered in Russia since 2012. The analysis of special indicators which is characterizing the burden of rotavirus infection in Russia is presenting definite interest for forecasting effectiveness of rotavirus vaccination.

\section{Methods}

\subsection{Population-Based and Laboratory-Based Surveillance Data}

We examined national population-based and enhanced laboratory-based surveillance data from Jun 2011 through Jun 2013 that was provided by both Enteric Pathogens Monitoring Group (FBIS Central Institute for Epidemiology) (EPMG), Official Statistic Department of Russia and passive surveillance system from the Centers of Hygiene and Epidemiology of Federal Service for Surveillance on Consumers' Rights Protection and Human Well-Being (Rospotrebnadzor). The data was collected from 83 regions, which were subdivided into eight federal districts. This data includes: the number of incidences rotavirus infection and distribution of morbidity by age, data of rotavirus outbreaks, and analysis of lethal cases for infants including toddlers and preschoolers, [P]G genotyping of rotavirus group A (RVgrA) data.

Cumulative frequency of rotavirus-related hospitalizations in age group 0 - 12 months (CfRG-12) was estimated like proportion of hospitalized children of age group 0 - 12 months in hospitalized children of age group 0 - 72 months due to special aspects of the surveillance system in Russia.

\subsection{Outbreaks of RVgrA}

Data of rotavirus infection outbreaks (more than five cases) were obtained from the national passive surveillance system as a part of the Centers of Hygiene and Epidemiology which belong to the Federal Service for Surveillance on Consumers' Rights Protection and Human Well-Being (Rospotrednadzor). This is a standard report issued every three months. There were two laboratory-based diagnostic methods used in the investigation of rotavirus outbreaks: ELISA-kit ("Rotavirus-antigen-EIA-BEST", VectorBest, Russia) which was used in 58\% of all outbreaks and RT-PCR-kit (“Amplisens ${ }^{\circledR}$ AII-screen-FRT PCR Kit”, FBIS CRIE, Russia) in 56\% of all outbreaks. Applying of combination both RT-PCR and ELISA methods was used in $14 \%$ of outbreaks.

\subsection{An Analysis of the Etiology of Lethal Cases in Children Accompanied by Diarrheal Disease}

All lethal cases among children younger than 5 years old where acute diarrheal disease was a primary, concurrent or associated disease, with or without accurate localization of a pathological process in gastrointestinal tract was included in this study. Given the possible association of lethal cases with a wide range of acute infectious diseases, accompanied by diarrheal symptoms, different types of autopsy samples from each case were tested for a wide range of pathogens such as Rotavirus gr. A, Rotavirus gr. C, Norovirus GII, Norovirus GI, Sapovirus, Adenovirus grF, Astrovirus, Shigella spp.+EIEC, Salmonella spp., Campylobacter spp. (thermophylic gr.), EHEC, ETEC, EAgEC, EPEC, Y. enterocolitica, Y. pseudo tuberculosis, Cronobacter (Enterobacter) sakazakii, Enterovirus gr. $A / B / C / D$, Influenza virus $A$, Influenza virus B, Human Respiratory Syncytial virus, human Parainfluenza virus-1-4, human Metapneumovirus, human Coronavirus, human Rhinovirus, human Adenovirus B, C, E, human Bocavirus, N. meningitidis, H. influenza, S. pneumonia, Mycoplasma pneumonia, Chlamydophila pneumonia, Listeria monocytogenes, Bordetella pertussis, Bordetella parapertussis, Bordetella bronchoseptica, HSV I, HSV II, CMV, EBV, HHV VI using set of Amplisens®-PCR-kits (FBIS CRIE, Russia) which utilizes real-time approach based on target-specific DNA probes. Interpretation as "positive result" in the case of simultaneous detection DNA or RNA target in different autopsy samples of given patients were based on levels of target DNA/RNA concentration.

\section{4. [P]G Genotyping RVgrA}

Stool samples from hospitalized children less than five years (sporadic cases) were collected to study [P]G ge- 
notype RVgrA distribution during seasonal peaks of rotavirus infection from February to March in 2012 and 2013. Samples were obtained from 11 regions of Russian Federation: the Republic of Dagestan, the Khabarovsk Krai, the Kamchatka Krai, the Moscow region, the Nizhniy Novgorod region, the Sverdlovsk region, the Novosibirsk region, the Irkutsk region, the Tomsk region, St-Petersburg and the Nenets Autonomous District. The AmpliSens ${ }^{\circledR}$ AII screen-FEP PCR Kit (FBIS CRIE, Russia) was used to confirm the presents of rotavirus A in the group's stools samples. Detection of [P]G-genotypes rotaviruses were found using the previously described method [11]. Additionally, typing of G9, G12 and [P]6 genotypes was performed using reverse-transcription real-time-PCR, the approach developed in our laboratory. Sets of primers and probes are listed in Table 1.

PCR assay was performed with a final reaction volume of $25 \mu$. The samples contained $5 \mu$ l PCR-mix-2-FRT (AmpliSens, Russia), 2.5 U of TaqF polymerase (AmpliSens, Russia), $176 \mu \mathrm{M}$ dNTPs (Biosan, Russia). The final concentrations of each pair of primers and fluorescently labeled probe were $0.36 \mu \mathrm{M}$ and $0.2 \mu \mathrm{M}$, respectively (Table 1). The common Tm value for all listed primer listed in Table 1 was chosen experimentally and was equal to $55^{\circ} \mathrm{C}$. The amplification reactions were performed in the RotorGene 6000 (Qiagen, Germany) under the following cycling conditions: 1 cycle at $95^{\circ} \mathrm{C} 15 \mathrm{~min} ; 45$ cycles at $95^{\circ} \mathrm{C} 10 \mathrm{~s}, 55^{\circ} \mathrm{C} 25 \mathrm{~s}$ and $72^{\circ} \mathrm{C} 10 \mathrm{~s}$. The fluorescence measurements were recorded at the detection step $\left(55^{\circ} \mathrm{C}\right)$ during each of the 45 cycles.

Samples with non-identified genotypes were sequenced for determining nucleotide sequence of VP4 and VP7 genomic regions using primer sets con2, con3, Beg9 and RG2 which were previously described [12] [13].

\section{Results}

According to obtained data, the RG incidence rate per 100,000 population in 2012 was 70.57, wherein the median value for all Russian regions was 69.3. In the level of 8 federal districts this index varied from 10.89 to 149.4 .

It was complicated to determine the cumulative frequency of rotavirus-related hospitalizations in 12 of 83 regions by reason of unsatisfactory diagnostics which were reflected in the low number of cases $\quad<100$ cases of rotavirus infection per year).

The cumulative frequency of rotavirus-associated hospitalizations (age group 0 - 12 months) over the whole territory of Russia comprised 26.3\% (2012), while in 8 federal districts it ranged from $22.2 \%$ to $32.1 \%$. In 10 regions a cumulative frequency of rotavirus-associated hospitalizations (age group 0 - 12 months) were less than $20 \%$, in 5 regions it was more than $40 \%$ (the Tyva Republic - 63.4\%, the Novosibirsk region- $52.2 \%$, Zabaykalsky Krai-48.9\%, the Sakha Republic-44.3\%, and the Republic of Buryatia—4.3\%).

In contradiction to the 2000-2011 period, in 2012 the occurrence in the age group less than 12 months decreased (1316 per 100,000) and was equal to the incidence in the age group 12 - 14 months (1318 per 100,000).

The number of rotavirus infection outbreaks during the 1 st season ( $\left(^{\text {st }}\right.$ June 2011 to $31^{\text {st }}$ May 2012) was 164 with 1934 affected people. In comparison the number of outbreaks during the $2^{\text {nd }}$ season (from $1^{\text {st }}$ June 2012 to

Table 1. Sequences of primers and probes used for typing of rotavirus strains.

\begin{tabular}{|c|c|c|c|}
\hline Primer & Sequence $^{\mathrm{a}}\left(5^{\prime}-3^{\prime}\right)$ & Position (strain, GenBank accession number) & [P]G type \\
\hline $12 \mathrm{G} 470$ & AATATTGTGTTAATACAGTACCAA & 460-483 (L26, M58290) & G12 \\
\hline $12 \mathrm{G} 700$ & ACCTCTTCAAAKGTTGTGAC & 701-682 (L26, M58290) & G12 \\
\hline $12 \mathrm{Gz}$ & $\left(\right.$ ROX $\left.^{c}\right)$ AGCGTTAGATGTYTCAGAACTTGCGCT(BHQ2 $\left.2^{b}\right)$ & 492-515 (L26, M58290) & G12 \\
\hline 9G80 & CTAACCTTTCTGATATCAATAGT & 76-98 (WI61, AB180969) & G9 \\
\hline 9G170 & AGGTGATGCAATAACAATAAGTA & 185-164 (WI61, AB180969) & G9 \\
\hline 9G130 & (ROX)CACTAACTAGTGCGATGGACT(BHQ2) & 122-142 (WI61, AB180969) & G9 \\
\hline $6 \mathrm{P} 160$ & TTGGARTCATGGRGAAGTG & 156-174 (ST3, L33895) & {$[\mathrm{P}] 6$} \\
\hline $6 \mathrm{P} 270$ & CTTGTTGATYAGTTGGATTCAA & 280-259 (ST3, L33895) & {$[\mathrm{P}] 6$} \\
\hline $6 \mathrm{Pz} 200$ & (ROX)CAACRATAGARCCAGTACTCGATGGT(BHQ2) & $185-210$ (ST3, L33895) & {$[\mathrm{P}] 6$} \\
\hline
\end{tabular}


31 May 2013) was 108 with 1012 affected people Figure 1.

An analysis of the etiology of 27 lethal cases in children less than 5 years old accompanied by diarrheal disease has shown only 9 cases with the presence of rotavirus RNA. In 4 cases, only the presence of Rotavirus A was revealed. However the remaining 5 cases were a combination of rotavirus infection with another pathogen which was most likely to be the main cause of lethal cases. In 4 of the last 5 cases the target DNA/RNA concentration of another pathogens were higher in comparison with the rotavirus (Salmonella spp., Human coronavirus, Campylobacter termophilic gr., Human astrovirus). Genotyping of these 9 cases revealed that rotaviruses from 8 cases belonged to the G4P [8] genotype and the last one was G2P [4]. The distribution of [P]G genotypes of RVgrA in Russia during the 2011-2012 and 2012-2013 seasons are shown in Table 2.

\section{Discussion}

Both the quality of RG diagnostics registered under passive surveillance and the true incidence influence the real morbidity level of the rotavirus infection (rotavirus gastroenteritis). During 2002 and 2012 the incidence of rotavirus infection in all age groups had increased four times from 17.5 to 70.6 per 100,000 population. Since 2010, the statistically significant growth of incidence (per 100,000 population) has not been registered (2010-72.0; 2011-69.6; 2012-70.6). Thus during 2002-2012 the contribution of different age groups to the incidence of rotavirus infection in children less than 72 months old has been constant: the age group less than 12 months old has formed 26\% - 33\%; age group 13 - 24 months old — $4 \%$ - 51\%; age group 25 - 72 months old-18\% - 23\% [11]. The percentage of children less than 4 years old has increased by $1 \%, 2 \%$ during this period [14]. Thus, the most likely cause of the RG incidence growth during the last 10 years is linked to the increased use of diagnostic kits for the RVgrA detection.

From the point of evaluation of the incidence rate as a criterion for identifying the quality of revealing RG, data obtained in Russia can be compared to the data available for other European states. So, the highest incidence levels (per 100,000) were registered in 2012 in Lithuania and Latvia (127.1 and 140.7); similar levels of incidence in 2012 were registered in Estonia (66.6), Poland (61.8); and lower levels of incidence at the same time were registered in England and Wales (26.3), Ukraine (20.04), Spain (5.3 in 2011) and Finland (3.87) [15] [16]. The direct comparison of incidences is inconvenient because of differences in reporting criteria of rotavirus gastroenteritis functioning in different countries.

Indicators of the age and RG cases distribution around Russia, characterizes it as an area with moderate activity of RVgrA circulation. However, there is an unusually high incidence of rotavirus-related hospitalizations (age group 0 - 12 months) in such regions as the Republic of Tuva, the Novosibirsk region, Zabaykalsky Krai, the Republic of Sakha and the Republic of Buryatia. These areas should be considered with highest priority for

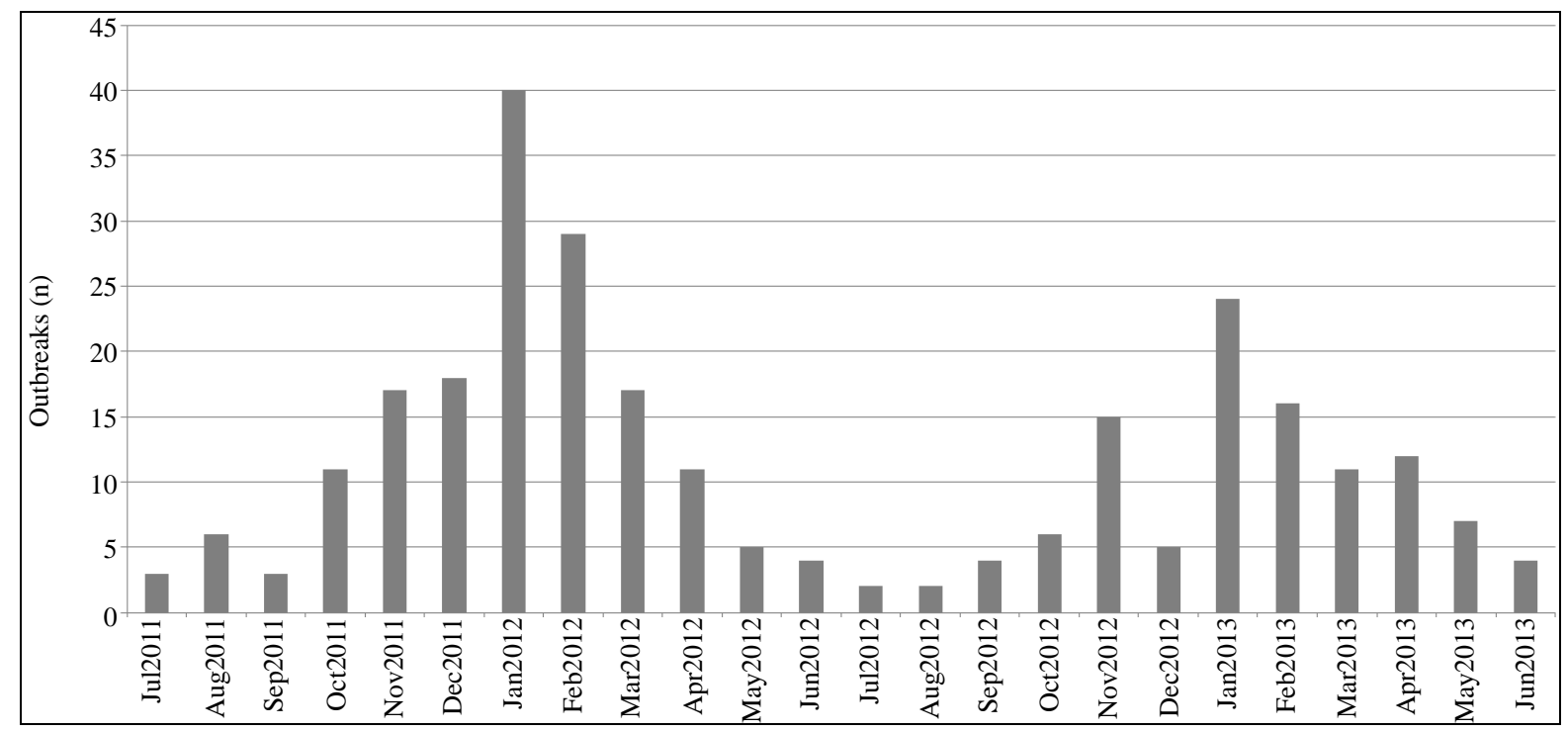

Figure 1. The outbreaks of rotavirus infection (rotavirus gastroenteritis) ( $>5$ cases) during the period from June 2011 to June 2013. 
Table 2. Distribution of [P]G genotypes of RVgrA in Russia, seasons 2011-2012 and 2012-2013.

\begin{tabular}{|c|c|c|c|c|c|c|c|c|c|c|c|c|c|}
\hline \multirow[b]{2}{*}{ Season 2011-2012 } & \multicolumn{13}{|c|}{ [P]G type Rotavirus grA } \\
\hline & \multicolumn{4}{|c|}{$G 1[P] 8 G 3[P] 8 G 4[P] 8 G 2[P] 4 C$} & \multicolumn{3}{|c|}{$G 9[P] 8$ G12[P]6 G3[P]9 G } & $312[P] 8 C$ & $G 4[P] 6 C$ & \multicolumn{2}{|c|}{$G 4[P] 4 G X[P] 8$} & Mixt & Total \\
\hline Moscow region (n) & 5 & 0 & 9 & 1 & 2 & 0 & 0 & 0 & 0 & 0 & 0 & 0 & 17 \\
\hline Republic of Dagestan (n) & 4 & 0 & 2 & 13 & 0 & 1 & 0 & 0 & 0 & 0 & 0 & 4 & 24 \\
\hline Tomsk region (n) & 12 & 4 & 28 & 0 & 0 & 0 & 0 & 0 & 0 & 0 & 0 & 2 & 46 \\
\hline St-Petersburg a(n) & 0 & 0 & 12 & 0 & 0 & 0 & 1 & 0 & 0 & 0 & 0 & 0 & 13 \\
\hline Khabarovsky Krai (n) & 2 & 5 & 6 & 1 & 0 & 0 & 0 & 0 & 0 & 0 & 0 & 1 & 15 \\
\hline N Novgorod region (n) & 1 & 0 & 4 & 0 & 4 & 0 & 0 & 0 & 0 & 0 & 0 & 2 & 11 \\
\hline Irkutsk region (n) & 0 & 0 & 16 & 0 & 0 & 0 & 0 & 0 & 0 & 0 & 0 & 1 & 17 \\
\hline Sverdlovsk region (n) & 7 & 0 & 11 & 0 & 2 & 0 & 0 & 0 & 0 & 0 & 0 & 0 & 20 \\
\hline Novosibirsk region (n) & 3 & 0 & 11 & 1 & 1 & 0 & 0 & 0 & 0 & 0 & 0 & 0 & 16 \\
\hline Nenets Autonomous District (n) & 19 & 0 & 1 & 0 & 0 & 0 & 0 & 0 & 0 & 0 & 2 & 0 & 22 \\
\hline Kamchatsky Krai (n) & 2 & 0 & 4 & 0 & 0 & 0 & 0 & 0 & 0 & 0 & 0 & 0 & 6 \\
\hline Total (n) & 55 & 9 & 104 & 16 & 9 & 1 & 1 & 0 & 0 & 0 & $2^{\mathrm{b}}$ & 10 & 207 \\
\hline season $2012-2013$ & & & & & & & & & & & & & \\
\hline Moscow region (n) & 3 & 0 & 15 & 3 & 3 & 0 & 0 & 1 & 0 & 0 & 0 & 1 & 26 \\
\hline Republic of Dagestan (n) & 1 & 0 & 8 & 1 & 1 & 1 & 0 & 0 & 0 & 0 & 2 & 0 & 14 \\
\hline Tomsk region (n) & 3 & 41 & 0 & 0 & 0 & 0 & 0 & 0 & 0 & 0 & 4 & 1 & 49 \\
\hline Khabarovsky Krai (n) & 3 & 9 & 16 & 2 & 7 & 0 & 0 & 0 & 0 & 0 & 0 & 3 & 40 \\
\hline N Novgorod region (n) & 0 & 0 & 19 & 0 & 0 & 0 & 2 & 0 & 0 & 0 & 0 & 4 & 25 \\
\hline Irkutsk region (n) & 9 & 0 & 11 & 6 & 1 & 0 & 0 & 0 & 1 & 1 & 0 & 1 & 30 \\
\hline Sverdlovsk region (n) & 6 & 0 & 14 & 1 & 1 & 0 & 0 & 0 & 0 & 0 & 0 & 2 & 24 \\
\hline Novosibirsk region (n) & 10 & 0 & 5 & 1 & 1 & 0 & 0 & 0 & 0 & 0 & 2 & 5 & 24 \\
\hline Nenets Autonomous District (n) & 0 & 0 & 0 & 7 & 0 & 0 & 0 & 0 & 0 & 0 & 0 & 0 & 7 \\
\hline Kamchatsky Krai (n) & 3 & 13 & 9 & 0 & 0 & 0 & 0 & 0 & 0 & 0 & 2 & 0 & 27 \\
\hline Total (n) & 38 & 63 & 97 & 21 & 14 & 1 & 2 & 1 & 1 & 1 & $10^{\mathrm{b}}$ & 17 & 266 \\
\hline
\end{tabular}

${ }^{\mathrm{a} D a t a}$ about genotypes in Saint-Petersburg only for 2011-2012; ${ }^{\mathrm{b}}$ Low level concentration of RVgrA.

the implementation of rotavirus vaccines in the regional immunization schedule.

The registration of outbreaks is an informative addition to the registration of sporadic cases to estimate the burden of RG. In many countries, this information has limited access, but some of the data is available through open sources. For instance, going to a total of only 1 to 12 outbreaks of RG affected people from a total of 6 to 97, had be reported in Ireland (total population $4.6 \mathrm{~m}$ ) in each year during 2005-2011 [17]. 1 - 2 outbreaks with up to 35 people had been registered in Scotland (population $5.2 \mathrm{~m}$ ) during 2010-2012 there [18]. Lastly, 60 - 74 outbreaks with up to 344 people had been reported in Hungary $(9.9 \mathrm{~m})$ in the years 2007-2009. The data above compared to Russia shows a sufficient level of revealing RG outbreaks under the implemented surveillance system.

Unfortunately, lethal outcomes accompanied by diarrhea symptoms are registered in all countries. The etiology of these diseases is diverse, because of the re-evaluation of the significance of the diarrhea syndromes under various infectious diseases. Identifying RVgrA in autopsy material is not always a strong indicator of the role of RG in the development of a fatal outcome and should be interpreted cautiously enough [19]. The spectrum of 
laboratory tests to determine the etiology, atypically severe and prolonged diarrheal illness should be as broad as possible. Identifying RVgrA should not be considered a reason for limiting or terminating the etiologic diagnosis search process.

The prevalence of different genotypes of RVgrA in Russia is highly heterogeneous, which is quite natural in view of the extensive area of the country. In general, genotype $4[\mathrm{P}] 8$ rotavirus is the most common across Russia. However, there were local variations during the period of observation of the dominant [P]G types in such regions as the Tomsk region (G4[P]8-G3[P]8), the Republic of Dagestan (G2[P]4-G4[P]8), the Novosibirsk region (G4[P]8-G1[P]8) and Nenets Autonomous District (G1[P]8-G2[P]4).

\section{Acknowledgements}

EPMG is kindly appreciated to the colleagues from Rospotrebnadzor institutions in the Republic of Dagestan, the Khabarovsky Krai, the Kamchatsky Krai, the Moscow region, the Nizhniy Novgorod region, the Sverdlovsk region, the Novosibirsk region, the Irkutsk region, the Tomsk region, St-Petersburg and the Nenets Autonomous District for the active participation in this study.

\section{Conflicts of Interest}

The authors declare no conflict of interest.

\section{References}

[1] Sanderson, C., Clark, A., Taylor, D. and Bolanos, B. (2011) Global Review of Rotavirus Morbidity and Mortality Data by Age and Region.

http://cdrwww.who.int/immunization/sage/meetings/2012/april/Sanderson_et_al_SAGE_April_rotavirus.pdf

[2] Parashar, U.D. and Glass, R.I. (2006) Public Health. Progress toward Rotavirus Vaccines. Science, 312, 851-852.

http://dx.doi.org/10.1126/science.1128827

[3] Vesikari, T. (1997) Rotavirus Vaccines against Diarrhoeal Disease. Lancet, 350, 1538-1541.

http://dx.doi.org/10.1016/S0140-6736(97)03254-6

[4] WHO (2009) Detailed Review Paper on Rotavirus Vaccines. http://cdrwww.who.int/immunization/sage/3_Detailed_Review_Paper_on_Rota_Vaccines_17_3_2009.pdf

[5] Meeting of the Immunization Strategic Advisory Group of Experts. April 2007-Conclusions and Recommendations (2007) Releve Epidemiologique Hebdomadaire/Section d'Hygiene du Secretariat de la Societe des Nations. Weekly Epidemiological Record/Health Section of the Secretariat of the League of Nations, 82, 181-193.

[6] WHO (2002) Generic Protocols for (i) Hospital-Based Surveillance to Estimate the Burden of Rotavirus Gastroenteritis in Children and (ii) a Community-Based Survey on Utilization of Health Care Services for Gastroenteritis in Children. http://whqlibdoc.who.int/hq/2002/WHO_V\&B_02.15.pdf

[7] Rotavirus Vaccines (2013) WHO Position Paper-January 2013. Releve Epidemiologique Hebdomadaire/Section d'Hygiene du Secretariat de la Societe des Nations. Weekly Epidemiological Record/Health Section of the Secretariat of the League of Nations, 88, 49-64.

[8] GlaxoSmithKline (2010) Rotarix ${ }^{\mathrm{TM}}$ Significantly Reduced Severe Rotavirus Gastroenteritis in African Babies during Their First Year of Life.

http://www.gsk.com/media/press-releases/2010/rotarix-significantly-reduced-severe-rotavirus-gastroenteritis-in-african -babies-during-their-first-year-of-life.html

[9] Postma, M.J., Jit, M., Rozenbaum, M.H., Standaert, B., Tu, H.A. and Hutubessy, R.C. (2011) Comparative Review of Three Cost-Effectiveness Models for Rotavirus Vaccines in National Immunization Programs; a Generic Approach Applied to Various Regions in the World. BMC Medicine, 9, 84. http://dx.doi.org/10.1186/1741-7015-9-84

[10] WHO (2008) Generic Protocol for Monitoring Impact of Rotavirus Vaccination on Gastroenteritis Disease Burden and Viral Strains. http://www.who.int/iris/handle/10665/69913

[11] Podkolzin, A.T., Fenske, E.B., Abramycheva, N.Y., Shipulin, G.A., Sagalova, O.I., Mazepa, V.N., et al. (2009) Hospital-Based Surveillance of Rotavirus and Other Viral Agents of Diarrhea in Children and Adults in Russia, 2005-2007. The Journal of Infectious Diseases, 200, S228-S233. http://dx.doi.org/10.1086/605054

[12] Gentsch, J.R., Glass, R.I., Woods, P., Gouvea, V., Gorziglia, M., Flores, J., et al. (1992) Identification of Group A Rotavirus Gene 4 Types by Polymerase Chain Reaction. Journal of Clinical Microbiology, 30, 1365-1373.

[13] Gouvea, V., Glass, R.I., Woods, P., Taniguchi, K., Clark, H.F., Forrester, B., et al. (1990) Polymerase Chain Reaction 
Amplification and Typing of Rotavirus Nucleic Acid from Stool Specimens. Journal of Clinical Microbiology, 28, 276-282.

[14] Federal State Statistics Service (2014) http://www.gks.ru/free_doc/new_site/population/demo/demo14.xls

[15] England, P.H. (2012) Laboratory Reports of Rotavirus Infections in England and Wales 2000-2012. http://www.hpa.org.uk/Topics/InfectiousDiseases/InfectionsAZ/Rotavirus/EpidemiologicalData/rota_DataEw/

[16] Epidemiología CNd (2011) Boletín Epidemiológico Semanal Vol 19. http://revista.isciii.es/public/journals/1/pdf_72.pdf

[17] Centre HPS (2011) HPSC Annual Reports 2011. http://www.hpsc.ie/hpsc/AboutHPSC/AnnualReports/File,13847,en.pdf

[18] Smith-Palmer, A., Pollock, K., Brownlie, S. and Cowden, J. (2012) Gastro-Intestinal and Foodborne Infections: Norovirus, Rotavirus, Cryptosporidium and Giardia—Laboratory Reports, 2011. HPS Weekly Report, 46.

[19] Podkolzin, A.T., Veselova, O.A., Yakovenko, M.L., Konovalova, T.A., Petukhov, D.N. and Yatsyshina, S.B. (2013) The Analysis of Structure of Lethal Outcomes in Young Children Suffering from Acute Diarrheal Infections. Infection Diseases, 11, 7. 